\title{
Developing Pupils' Language in Primary School Based on Technology
}

\author{
Georgeta Pânișoară \\ Cristina Sandu \\ Silvia Făt \\ lulia Lazăr \\ Liliana Mata \\ University of Bucharest/ University of Bacău
}

\begin{abstract}
This study aims to identify the level of language difficulties for children in primary school and to open teachers to use virtual methods in teaching through technology. The participants in this study were 122 Romanian teachers with different levels of experience. The method used was a questionnaire created by ourselves to which we applied the Cronbach alpha index to measure the fidelity of each item. The questionnaire aimed at identifying the sources of speech difficulties, teaching methods used by teachers, and teachers' perceptions about the use of technology and its effectiveness in relieving language difficulties. The results of this research were introduced into statistical interpretation programs to confirm the hypotheses, the data obtained confirmed the use of teaching methods by teachers and their opening to the combination of technology in didactic activity.
\end{abstract}

Keywords: language, technology, digital learning, virtual reality

\section{Introduction}

\section{Theoretical foundation}

In the new era of information technology, thinking and communication are crucial for students to master world class knowledge and contribute towards the building of a modern and progressive society. Pupils, developing their communication skills, can have personal and professional achievements; can become successful people; can shine in social life; can reach emotional, social and economic maturity (Ngang, Nair, Prachak, 2014).

The development of language is closely related to the child's early relationships and experiences (Van Scoter, 2008). The importance of playing at an early age and the familiarization of children with everything that involves digital technology, these games being the one that gives the uniqueness of building reading and writing skills for each child (Toki, Pange, 2010). Using speech technology contributes to building educational environments, improving the quality of speech therapy, so digital technology and resources can be considered tools for change and innovation in speech therapy. (Tezci, 2009). Massaro and Light (2004) helped to improve language articulation by using a computer-animated speaker (Baldi). Another example is SpeechKit, a multimedia program that can be used by speech therapists to support people with associated communication difficulties (Calder, 2008)

An important aspect for the efficiency of speech therapy is the use of intelligent diagnostics and therapies, a viable alternative to traditional approaches and aimed at increasing the efficiency of speech therapy (Popovici, Buică and Velican, 2010). The language as a vital part of children's development provides opportunities for learning, for communicating and building relationships with others as well as for enabling children to make sense of the world around them (Brock, Rankin, 2008). It is well recognized that interacting with more qualified speakers, providing a rich home and school environment and engage in interactive book reading are important activities to support the development of the language preschool age children (Berk, 2013). 
Research studies in language area for students indicate that technological development is very important and effective in learning the language. The technology, internet and some computer games could promote language positively if they are used correctly. Gee (1996) mentions sociocognitive approach gives language learners chances to interact in an authentic social context. Internet can provide sociocognitive approach through authentic tasks and project based studies. Online games can support and improve various vocabulary fields and also give valuable language feedback. (Pensky, 2002)

Technology makes a positive effect not only on social life but also on education. Since technology becomes increasingly prevalent within educational settings, there emerges an expectation for educators to utilize digital tools to support classroom teaching and learning. However, the rapidly changing technological innovations about the education make it harder for the teachers (Kingsley, 2007). Technology changes so fast that it is almost impossible to follow for the teachers. Nonetheless, although most teachers throughout the world still use chalk and blackboard, technological devices are used frequently in language developement classrooms all over the world to provide supplementary practice in the language development. The digital society we live in, also referred to as the information society, is driven by information and communication technologies which allow people to produce and share data unboundedly (Webster, 2006 in Panisoara et al., 2017).

Virtual learning is an excellent method of targeting learners who are not able to participate the formal class sessions in an educational institution due to the priorities of work, home, or some regulation limitations. However, distance education has also another aspect which is emerging in new colleges where education authorities encounter shortage of school members for offering specialized courses. (Bidaki, Semnani, 2013)

The definition „,virtual reality" nowadays is used very actively not only in the sphere of computer techniques as by representatives of different fields of man's vital activity. The process of training mainly seems to be virtual and may be apprehended like interaction of virtual spaces, and people in this case fulfill a function of bearers or like a process of coping and appropriating strange virtual spaces. The role of virtual reality in professional activity of a teacher of technology is analyzed through relativity of professional activity space as a main sign, distinguishing it from space and it displaying in functional, valuable and emotional spheres. (Akhmetov, Faizrakhmanov, Faizrakhmanova, 2015)

\section{Research Design}

\section{II.1. Purpose of the research:}

Identifying the language difficulties of pupils in primary classes, and the methods used. by teachers to diminish them. Technology can provide many opportunities to achieve this goal.

\section{II.2. Research objectives:}

- Define the language difficulties encountered by teachers among the students and measure the impact on learning and socialization in schooling;

Find the best solutions, where digital resources can have a certain degree of efficiency;

Establish the role of teacher in preventing, identifying and remedying these difficulties.

\section{II.3. Hypotheses}

There is a high level of language difficulties encountered in pupils in primary classes.

Teachers in primary classes apply interactive teaching methods so that children's speech problems are ameliorated.

There is a high degree of teachers' openness to the use of technology in activities.

II.4. Research Method: Several specialists have built a questionnaire in a launched survey among teachers with different level of experience in teaching and speech development.

II.5. The sample consisted of 122 teachers whose teaching experience ranges between $1-3(57 \%), 3-5(33 \%) 10(7 \%)$, and over 10 years (3\%). 


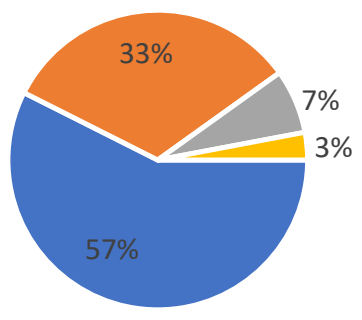

- 1-3 years

- 3-5 years

- 5-10 years

- over 10 years

Figure 1. Teaching experience

\section{Results}

The language development is important at any age. The age of small schooling is branded by a remarkable potential. If it is not activated, the losses are high and the recoveries are partial for all these children.

Typology, sources and frequency of speech difficulties - Recently, teachers observed there has been an increase in the number of pupils who have communication difficulties. In our research, $90 \%$ noticed this reality, particularly visible at school, where pupils' performance is conditioned by language issues. Oral and written expression are significant aspects of school success, defined as a child's ability to meet school requirements. Language is also a practical tool, to which educators and parents must equally contribute. The following reasons refer to the fact that the specialists do not get involved enough $(7 \%)$ and that the therapy, psychological or logopedic, has quite high costs in our country (10\%). School absences does not appear to be a frequent source, showing the child's participation rate in school activities is high. This behavior can be specific to urban school. In some cases (4\%), teachers do not show enough interest in language education or teaching-learning methods used actually in school are inadequate. A few teachers mentioned, in free answers, that students spend all their free time in front of the computer.

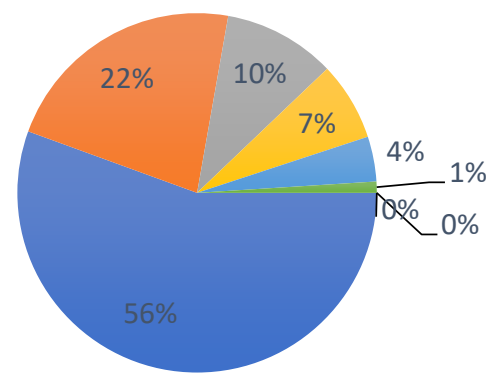

lack of parent

involvement

poor collaboration

between parent and

educator

the high costs of

therapy

Figure 2. Language difficulties sources

For the majority of respondents, over $80 \%$, many disorders were diagnosed by the specialist. In their grading, were mentioned (see figure 3):

1. substitutions, omissions, letter inversions;

2. alteration of different sound;

3. difficulties in reading-writing;

4. inadequate tempo, rhythm, fluency of language;

5. hearing impairment; 
6. unsettling the reading process;

7. articulatory immaturity such as dyslalia.

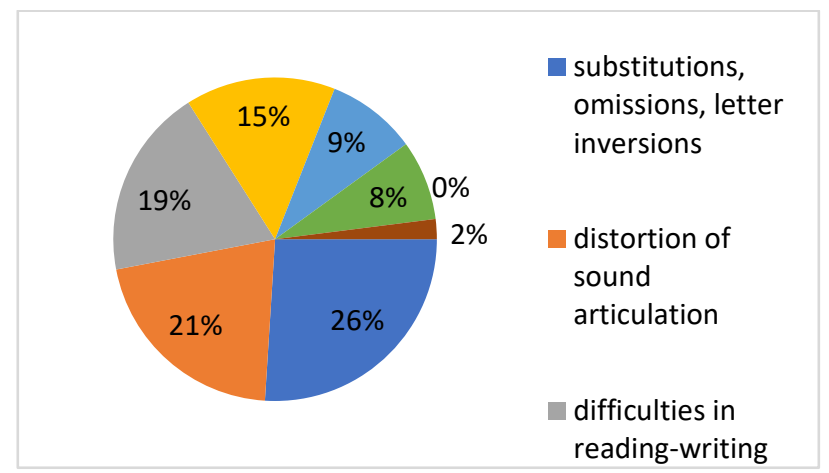

Figure 3. Diagnosed disorders

For those that mentioned a disorder $(47,7 \%)$, there is a specific form of manifestation, in a medium and easy stage. Only $4 \%$ of teachers have experienced a serious form of language disorder, accompanied by additional medical complications.

The language development methods - Usually, teachers practice in primary school a large number of methods and techniques, language training tools and forms, and textbooks for lessons design and application. Although the differences between these resources are small, the most useful methods for developing language at school are (see figure 4)

1. conversation-based methods - $21 \%$

2. games- $18 \%$

3. reading - $18 \%$

4. methods of group communication $-17 \%$

5. creative methods $-15 \%$

6. narrative stories $11 \%$

7. reading-writing

The conversation techniques make the speech easy or difficult, in order to understand and fix words in individual vocabulary. Words must be integrated in into a system of relationships. Besides conversation, a popular form of developing pupils' language is the game. By content, language learning games can be ways: to form a correct pronunciation and phonematic hearing; for enhancing the active and passive vocabulary of children.

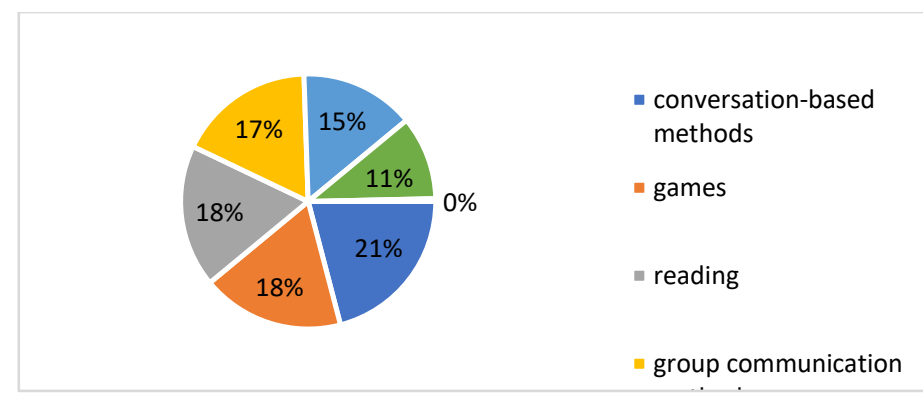

Figure 4. Learning methods

The technology usage - In relation to the teachers' opinion on the efficiency of technology in language education, their answers reflect a moderate attitude. Over a half of respondents $(51 \%)$ show a neutral attitude. $26 \%$ and $17 \%$ consider that technology would be very useful in language learning activities (see figure 5). The open attitude of the teaching staff for the 
use of technology in educational instructive activity represents a an element that leads us to a high degree of progress and efficiency.

\begin{tabular}{lllll}
\hline Group Statistics & $\mathrm{N}$ & Mean & Std. Deviation & Std. Error Mean \\
\hline questionnaire & 122 & 46.0714 & 5.33831 & .51853 \\
\hline
\end{tabular}

Table 1. Descriptive statistics

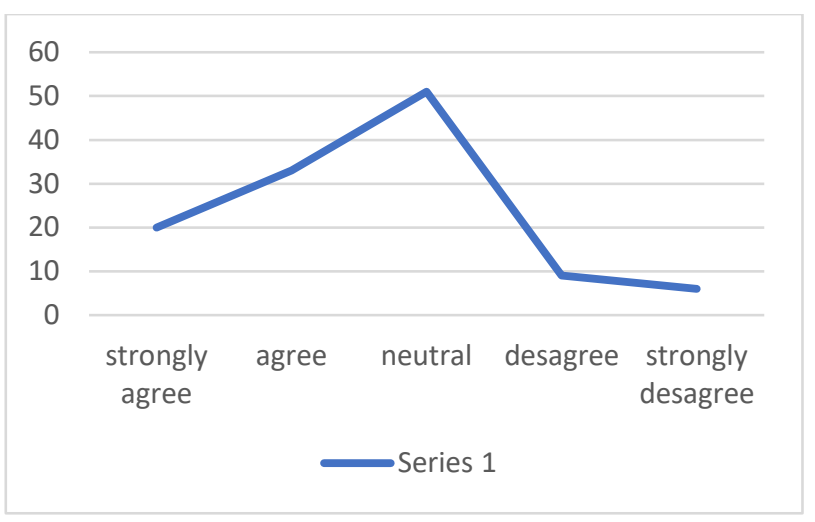

Figure 5. Teachers' opinion on the efficiency of technology

The questioned teachers were asked to give an example of an efficient virtual method for language development. As we see below (see figure 6), next methods have a various choice: interactive games (46\%); audition (20\%); digital lecture (16\%); electronic exercises (10\%); electronic testing (5\%); virtual simulation (3\%).

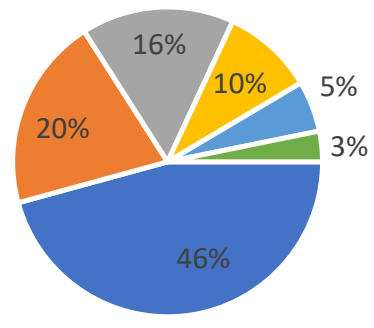

\section{- interactive game}

- audition

- digital lecture

= electronic

exercices

Figure 6. Virtual methods

Interactive games create a good motivation for communication and develop children's initiative, attention, imagination, and creativity. Digital language learning applications have an obviously adaptive potential: feedback immediate alert signaling, analysis and offering multiple alternatives, selective responses, possibilities to individualize the language development methods.

\section{Conclusions}


The teachers seem to be dissatisfied with communication with family in the case of children with language difficulties. School-family partnership is poorly represented in many situations. Technology is an appropriate means of helping to remediate some difficulties of speech, but this is not a unique, miraculous solution. The option for digital resources is at a neutral level. This is not a surprising conclusion, considering that Romanian teachers need many resources to use technology at its real potential. At this moment, there is a lack of resources. Speech difficulties are important aspects of student learning. They have a relationship of mutual conditioning. The teacher has the responsibility to create a good framework of communication situations, more or less formal, based on clear objectives, included in a coherent program. This also implies prevention, diagnosis and improvement. For this, technology can be an effective resource.

\section{References}

[1] Akhmetov, L.G., Faizrakhmanov, I.M., Faizrakhmanova, A.L. 2015), Virtual Reality in Professional Activity of A Teacher of Technology, Procedia, Social and Behavioral Sciences, 191, 2812-2816.

[2] Berk, L.E. (2013), Dialogic Shared Storybook Reading: An Instructional Technique for Use with Young Students in Inclusive Settings, Reading \&Writing Quarterly: Overcoming Learning Difficulties, 21, 307-313.

[3] Bidaki, M, Semnani, M. ( 2013), Students' attitude towards two different virtual methods of course delivery, Procedia, Social and Behavioral Sciences, 83, 862-866.

[4] Brock, A., Rankin, C. (2008), Communication, Language and Literacy from Birth to Five. London: Sage

[5] Calder, D. 2008. Speechkit: A multimedia speech tool. In Proceedings of the ACM Conference on Information Integration and Web-based Applications andServices, pp. 647-650.

[6] Gee, J. P.(1996), Social linguistics and literacies. London: Taylor and Francis.

[7] Kingsley, K. V. (2007), Empower diverse learners with educational technology and digital media. Intervention in school and clinic, 43(1), 52-56.

[8] Massaro, D. W., Light, J. (2004). Using Visible Speech to Train Perception and Production of Speech for Individuals With Hearing Loss, Journal of Speech, Language, and Hearing Research, vol.47, pp.304-320.

[9] Ngang, T., Nair, S., Prachak, B. (2014), Developing instruments to measure thinking skills and problem solving skills among Malaysian primary school pupils. Procedia, Social and Behavioral Sciences, 116, 37603764

[10] Pânişoară, G., Pânişoară, I.O., Sandu, C., Chirca, R. (2017). The Status of Positive Psychology Strengths within the Romanian School in the Digital Society. BRAIN. Broad Research in Artificial Intelligence and Neuroscience, , 4, 5-22.

[11] Popovici, D. V., Buică, C. B.,Velican, V. (2010). Intelligent systems for the diagnosis and therapy of speechlanguage disorders. Romanian Journal of Experimental Applied Psychology,vol, 1, pp.60-64

[12] Prensky, M. (2002), Digital game-based learning. New York. Paragon House.

[13] Tezci, E. (2009). Teachers' effect on ICT use in education: the Turkey sample. Procedia Social and Behavioral Science, vol.1, pp. 1285-1294.

[14] Toky, E., Pange, J. (2010). E-learning activities for articulation in speech language therapy and learning for preschool children. Procedia Social and Behavioral Sciences, vol.2, pp. 4274-4278

[15] Van Scoter, J. (2008). The potential of it to foster literacy development in kindergarten, International Handbook of Information Technology in Primary and Secondary Education, pp. 149-161. 